\title{
Ion Migration in Organometal Trihalide Perovskite and Its Impact on Photovoltaic Efficiency and Stability
}

\author{
Published as part of the Accounts of Chemical Research special issue "Lead Halide Perovskites for Solar Energy \\ Conversion".
}

\author{
Yongbo Yuan and Jinsong Huang* \\ Department of Mechanical and Materials Engineering, University of Nebraska-Lincoln, Lincoln, Nebraska 68588-0656, United \\ States
}

CONSPECTUS: Organometal trihalide perovskites (OTPs) are emerging as very promising photovoltaic materials because the power conversion efficiency (PCE) of OTP solar cells quickly rises and now rivals with that of single crystal silicon solar cells after only five-years research. Their prospects to replace silicon photovoltaics to reduce the cost of renewable clean energy are boosted by the lowtemperature solution processing as well as the very low-cost raw materials and relative insensitivity to defects. The flexibility, semitransparency, and vivid colors of perovskite solar cells are attractive for niche applications such as built-in photovoltaics and portable lightweight chargers. However, the low stability of current hybrid perovskite solar cells remains a serious issue to be solved before their broad application. Among all those factors that affect the stability of perovskite solar cells, ion migration in OTPs may be intrinsic and cannot be taken away by device encapsulation.

The presence of ion migration has received broad attention after the report of photocurrent hysteresis in OTP based solar cells. As suggested by much direct and indirect experimental evidence, the ion migration is speculated to be the origin or an important contributing factor for many observed unusual phenomenon in OTP materials and devices, such as current-voltage hysteresis, switchable photovoltaic effect, giant dielectric constant, diminished transistor behavior at room temperature, photoinduced phase separation, photoinduced self-poling effect, and electrical-field driven reversible conversion between lead iodide $\left(\mathrm{PbI}_{2}\right)$ and methylammonium lead triiodide $\left(\mathrm{MAPbI}_{3}\right)$. Undoubtedly thorough insight into the ion-migration mechanism is highly desired for the development of OTP based devices to improve intrinsic stability in the dark and under illumination. In this Account, we critically review the recent progress in understanding the fundamental science on ion migration in OTP based solar cells. We look into both theoretical and experiment advances in answering these basic questions: Does ion migration occur and cause the photocurrent hysteresis in perovskite solar cells? What are the migrating ion species? How do ions migrate? How does ion migration impact the device efficiency and stability? How can ion migration be mitigated or eliminated? We also raise some questions that need to be understood and addressed in the future.

\section{INTRODUCTION}

The ion-migration behavior in organometal trihalide perovskites (OTPs) had not cause strong interest until the report of obvious photocurrent hysteresis in OTP solar cells, despite ion migration in halide based perovskite materials being known for over 30 years. ${ }^{1}$ At the 2013 MRS fall meeting, Hoke and Snaith reported the presence anomalous photocurrent densityvoltage $(J-V)$ hysteresis in mesostructure OTP devices (Figure 1a) and Snaith speculated ion migration driven by the electric field to be one of the three possible origins of photocurrent hysteresis. $^{2}$ Xiao et al. discovered the giant switchable photovoltaic effect in early 2014 where the photocurrent direction was completely flipped during scanning in OTP solar cells with a planar heterojunction structure and symmetric electrode. $^{3}$ This provided the first evidence for the electric-field changed morphology of the OTP materials and proved that the ion migration effect was a very important contribution to the photocurrent hysteresis by excluding the other two possible factors such as ferroelectricity. Switchable device polarity was also observed in OTP solar cells with different device configurations (both vertical and lateral structure), different hybrid perovskite materials (e.g., methylammonium (MA) lead triiodide $\left(\mathrm{MAPbI}_{3}\right)$, methylammonium lead bromide $\left(\mathrm{MAPbBr}_{3}\right)$, and formamidinium lead triiodide $\left.\left(\mathrm{FAPbI}_{3}\right)\right)$, or different electrode materials (e.g., gold $(\mathrm{Au})$, platinum, nickel, carbon, or gallium), demonstrating that ion migration is general and intrinsic to the OTP materials. Later, Tress et al. ${ }^{4}$ also

Received: September 14, 2015

Published: January 28, 2016 
(a)

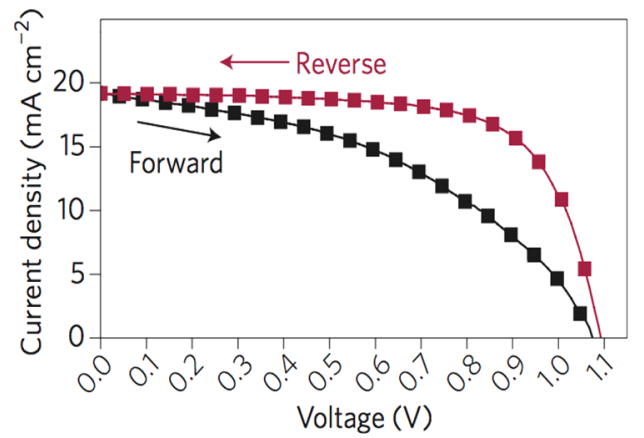

(c)

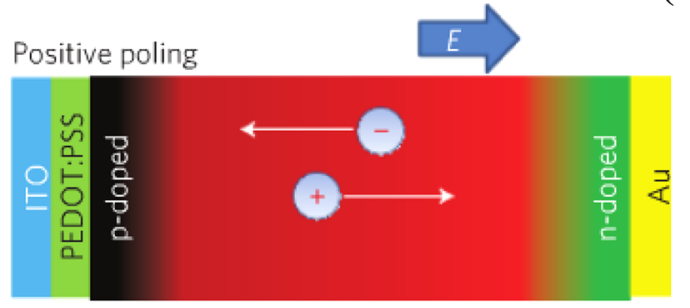

(b)
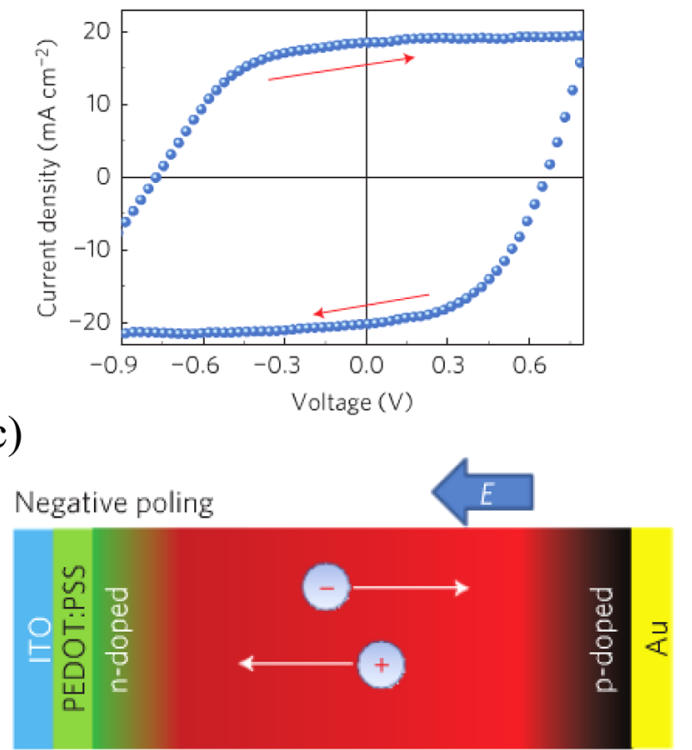

Figure 1. Typical photocurrent curves of OTP solar cells with nonsymmetrical (panel a, Reproduced with permission form ref 2 c. Copyright 2014 Nature Publishing Group) and symmetrical electrode work functions (b) and (c) schematics of ion migration in perovskite during positive and negative poling, respectively. Panel $b$ and $c$ reproduced with permission form ref 3. Copyright 2015 Nature Publishing Group.

suggested ion migration among other mechanisms as a contribution for the photocurrent hysteresis although no direct evidence of ion migration was shown.

More unusual phenomena have been observed on OTP materials and devices, which may also originate from the ionmigration effect. One example is the open challenge to obtain a high-mobility OTP transistor despite the reported Hall mobilities of OTP materials $\left(\sim 100 \mathrm{~cm}^{2} /(\mathrm{V} \mathrm{s})\right.$ for $\left.\mathrm{MAPbI}_{3}\right)$ being comparable to that of silicon. ${ }^{5}$ This can be explained by the screening of the gate field by the accumulation of migrated ions at the gate dielectric/perovskite interface. Chin et al. showed that cooling the OTP transistor devices to freeze the ion migration $(<200 \mathrm{~K})$ made the $\mathrm{MAPbI}_{3}$ transistor work with a reasonably good mobility. ${ }^{6}$ The other example is the giant static dielectric constant of OTP materials $\left(\sim 10^{6}\right.$ for $\mathrm{MAPbI}_{3-\mathrm{x}} \mathrm{Cl}_{x}$ ) measured under one sun illuminating conditions at low frequency $(\sim 0.1 \mathrm{~Hz})$, as reported by Juarez-Perez et al. ${ }^{7}$ Ion conduction was shown to be one possible origin of the photoinduced giant permittivity and $1 / f$ dependent on static dielectric constant. ${ }^{8}$ Other possible origins such as chargetrapping effects may also cause the giant static dielectric constant.

In this Account, we provide a critical review on the advances in understanding ion-migration science in OTP materials from both theoretical and experimental aspects and summarize its impacts on perovskite photovoltaic device stability and efficiency. Here we focused on the material of $\mathrm{MAPbI}_{3}$ because it has been heavily studied for solar cell applications with very high efficiency obtained, although ion migration also was shown to occur for all other OTP materials. ${ }^{3}$

\section{WHAT IS MIGRATING IN THE OTP FILMS UNDER THE ELECTRIC FIELD?}

The first question to be answered for ion migration is which ion or ions migrate in the $\mathrm{MAPbI}_{3}$ films. Any of the constituting ions (i.e., $\mathrm{I}^{-}, \mathrm{Pb}^{2+}$ and $\mathrm{MA}^{+}$) may migrate. Additional species resulting from material decomposition or contamination, such as $\mathrm{H}^{+}$, may also join the game. ${ }^{9}$ How easily an ion migrates in a solid material is characterized by the activation energy $\left(E_{\mathrm{A}}\right)$, and the migration rate $\left(r_{\mathrm{m}}\right)$ is influenced by the $E_{\mathrm{A}}$ as $r_{\mathrm{m}} \propto \exp \left(-\frac{E_{\mathrm{A}}}{k_{\mathrm{B}} T}\right)$, where $k_{\mathrm{B}}$ and $T$ are Boltzmann constant and temperature, respectively, and $k_{\mathrm{B}} T$ represents thermal activation energy. The $E_{\mathrm{A}}$ is sensitive to the material's crystal structure, ionic radius, ion-jumping distance, and the charge of ions. Generally ions migrate faster in crystals with more and bigger available interstitial sites, smaller and less charged ions, and smaller jumping distance. Taking the well-studied $\mathrm{ABO}_{3}$ structure oxide perovskites as analogy, $\mathrm{I}^{-}$may be the migrating species in $\mathrm{MAPbI}_{3}$, analogous to the $\mathrm{O}^{2-}$ ions in the oxide perovskites. In the $\mathrm{MAPbI}_{3}$, the $\mathrm{I}^{-}$ions in the edge of the $\mathrm{PbI}_{6}{ }^{4-}$ octahedron have a shorter distance with the nearest $\mathrm{I}^{-}$ vacancy $(\sim 4.46 \AA)$ than $\mathrm{MA}^{+}$and $\mathrm{Pb}^{2+}$ ions $(\sim 6.28 \AA$ ) (Figure $2)$. Although the radius of $\mathrm{I}^{-}$ions $(0.206 \mathrm{~nm})$ is large, the migration of the halide ions in other $\mathrm{ABX}_{3}$ perovskite, such as $\mathrm{CsPbI}_{3}$ and $\mathrm{CsPbBr}_{3}$, has been proven using "Tubant's method" previously. ${ }^{1}$ It is thus quite reasonable to speculate that $\mathrm{I}^{-}$ions are the most likely mobile ions in $\mathrm{MAPbI}_{3}$.

Theorists already did first-principle calculations on the $E_{\mathrm{A}}$ of different ion migrations through Schottky defects. Eames et al. compared the calculated $E_{\mathrm{A}}$ for the migration of $\mathrm{I}^{-}, \mathrm{Pb}^{2+}$, and $\mathrm{MA}^{+}$ions in $\mathrm{MAPbI}_{3}$ and suggested that $\mathrm{I}^{-}$is the most mobile ion. ${ }^{10}$ In their model, $\mathrm{I}^{-}$migrates along the $\mathrm{I}^{-}-\mathrm{I}^{-}$edge of the $\mathrm{PbI}_{6}$ octahedron (path $\mathrm{A}$ in Figure $2 \mathrm{~b}$ ) with a slightly curved pathway (Figure $2 \mathrm{a}$ ) with the lowest $E_{\mathrm{A}}$ of $0.58 \mathrm{eV}$; the migrating of $\mathrm{MA}^{+}$in the (100) plane along $\langle 100\rangle$ direction (path $\mathrm{D}$ in Figure $2 \mathrm{~b}$ ) has a higher $E_{\mathrm{A}}$ of $0.84 \mathrm{eV}$, and the $\mathrm{Pb}^{2+}$ migrating along the diagonal of the unit cell $(\langle 110\rangle$ direction, path $\mathrm{B}$ in Figure $2 \mathrm{~b})$ has a much higher $E_{\mathrm{A}}$ of $2.31 \mathrm{eV}$. Eames et al. derived an $E_{\mathrm{A}}$ of $0.60-0.68 \mathrm{eV}$ from photocurrent relaxation at biased preconditioning, which is close to their calculated $E_{\mathrm{A}}$ of $\mathrm{I}^{-}$ion migration. The majority of mobile ions were hence suggested to be the $\mathrm{I}^{-}$ions, which are estimated to have a diffusion coefficient of $10^{-12} \mathrm{~cm}^{2} \mathrm{~s}^{-1}$ at $320 \mathrm{~K}$. In another 
(a)

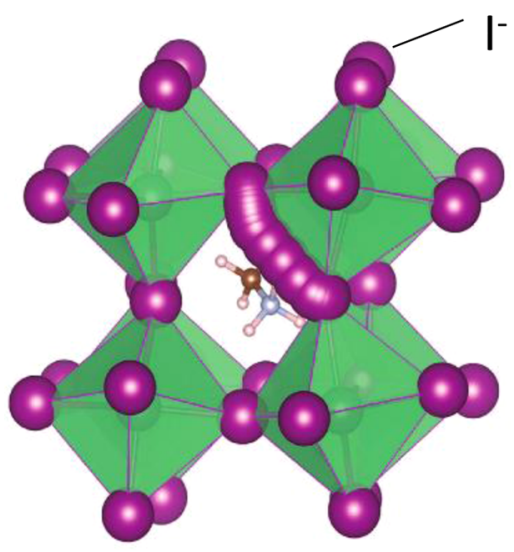

(b)

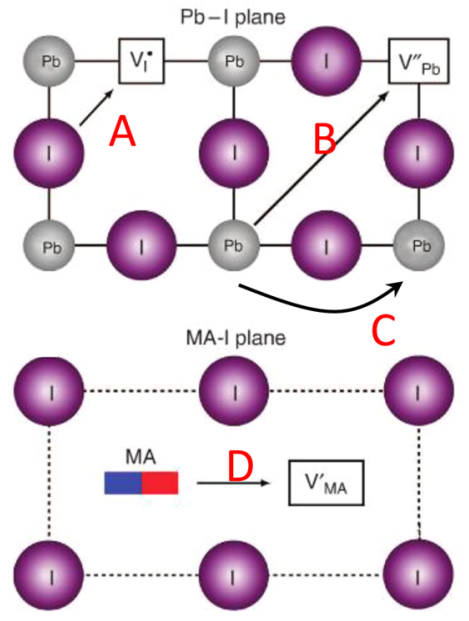

(c)

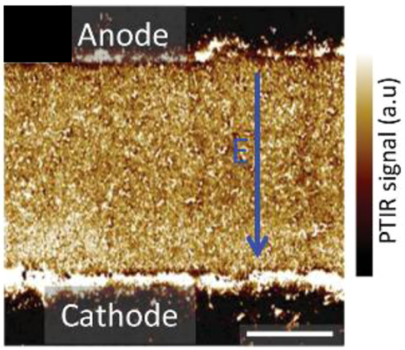

Before bias

(d)

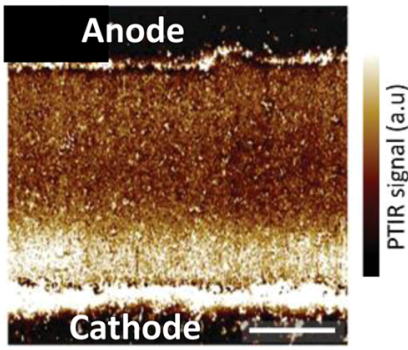

After $100 \mathrm{~s}$

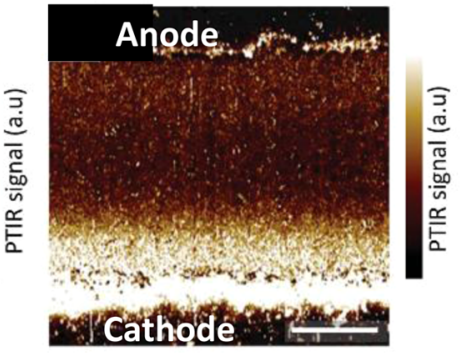

After $200 \mathrm{~s}$

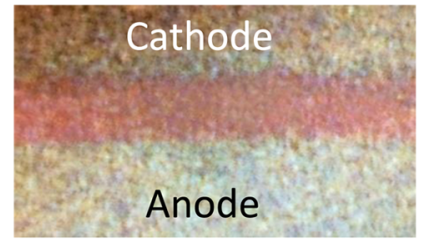

Before bias
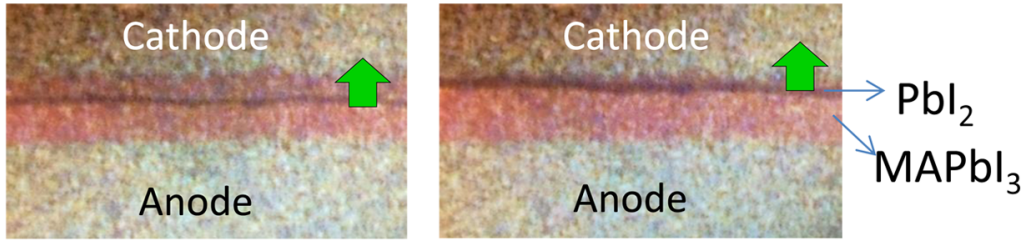

Under applied bias

Figure 2. (a) Migration path of $\mathrm{I}^{-}$ions along the $\mathrm{I}^{-}-\mathrm{I}^{-}$edge of the $\mathrm{PbI}_{6}{ }^{4-}$ octahedron in the $\mathrm{MAPbI}_{3}$ crystal calculated from density functional theory (DFT) method. (b) Illustration of the migration paths for $\mathrm{I}^{-}$ions (A), $\mathrm{Pb}^{2+}$ ions $(\mathrm{B}, \mathrm{C})$ in the $\mathrm{Pb}-\mathrm{I}$ plane, and $\mathrm{MA}^{+}$ions (D) in the MA-I plane that was used for the calculation of activation energies. Reproduced with permission form ref 10. Copyright 2015 Nature Publishing Group. (c) PTIR images of the distribution of $\mathrm{MA}^{+}$before and after electrical poling for 100 and $200 \mathrm{~s}$, where the electrode spacing is $100 \mu \mathrm{m}$. Reproduced with permission form ref 11 . Copyright 2015 Wiley. (d) Optical images of the lateral $\mathrm{MAPbI}_{3}$ perovskite solar cell with a mobile $\mathrm{PbI}_{2}$ thread, which formed and migrated at $330 \mathrm{~K}$ along the applied electrical field direction. Reproduced with permission form ref 12 . Copyright $2015 \mathrm{Wiley}$.

theoretical work, Azpiroz et al. calculated the $E_{\mathrm{A}}$ to be 0.08 , 0.80 , and $0.46 \mathrm{eV}$ for the $\mathrm{I}^{-}, \mathrm{Pb}^{2+}$ (path $\mathrm{C}$ in Figure $2 \mathrm{~b}$ ), and $\mathrm{MA}^{+}$ions, respectively. ${ }^{13}$ Due to the very small $E_{\mathrm{A}}$ for $\mathrm{I}^{-}$ions, Azpiroz et al. estimated that the $\mathrm{I}^{-}$ions can migrate through the $\mathrm{MAPbI}_{3}$ film within $1 \mu \mathrm{s}$, which is too fast to explain the hysteresis effect or photovoltaic switch rate in the $\mathrm{MAPbI}_{3}$ devices $^{3}$ (typically in a time scale of $0.1-100 \mathrm{~s}$ ). The majority ions that cause the observed slow current response was hence suggested by Azpiroz et al. to be $\mathrm{MA}^{+}$or $\mathrm{Pb}^{2+}$ ions. Later, Haruyama et al.'s calculation gave an $E_{\mathrm{A}}$ of $0.33 \mathrm{eV}$ for $\mathrm{I}^{-}$ migration and an $E_{\mathrm{A}}$ of $0.55 \mathrm{eV}$ for $\mathrm{MA}^{+}$migration. ${ }^{14}$ To summarize, although the different computational models gave very different $E_{\mathrm{A}}$ values, their concensus is that $\mathrm{I}^{-}$ions are more readily mobile than $\mathrm{MA}^{+}$and $\mathrm{Pb}^{2+}$ ions. It is noted that none of these models consider ion migration through the interstitial sites (Frenkel defects). However, the calculated formation energies of the interstitial defects for $\mathrm{I}^{-}(0.23-0.83 \mathrm{eV})$ and $\mathrm{MA}^{+}(0.20-0.93 \mathrm{eV})$ are actually close to the $E_{\mathrm{A}}$ for $\mathrm{I}^{-}$(e.g.,
$0.58 \mathrm{eV}$ ) and $\mathrm{MA}^{+}$(e.g., $\left.0.84 \mathrm{eV}\right)$ migration. ${ }^{15}$ This indicates that more theoretical work needs to consider other possible ion migration scenarios to understand ion migration in OTPs. $\mathrm{H}^{+}$is the only species that has been speculated to migrate through Frenkel defects because of its smallest size. Egger et al. calculated a $E_{\mathrm{A}}$ of $0.29 \mathrm{eV}$ for $\mathrm{H}^{+}$migrates along a transient hydrogen bond connecting two equatorial iodides. ${ }^{9}$ It is vital to have experimental evidence to verify this possibility.

The first experimentally confirmed migrating species was $\mathrm{MA}^{+}$. The recently developed photothermal induced resonance (PTIR) microscopy enables the direct imaging of $\mathrm{MA}^{+}$ distribution because it combines the Fourier transform infrared spectroscopy (FTIR) chemical signal and AFM imaging capability. Yuan et al. observed a redistribution of $\mathrm{MA}^{+}$ions (Figure 2c) after an electric poling in a lateral $\mathrm{MAPbI}_{3}$ solar cell. ${ }^{11}$ After application of a small electrical field of $1.6 \mathrm{~V} / \mu \mathrm{m}$ for $100 \mathrm{~s}, \mathrm{MA}^{+}$ions depleted from the center and the anode region and accumulated around the cathode region (Figure 2c), 
(a)

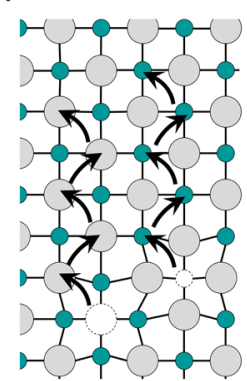

Schottky defects (b)

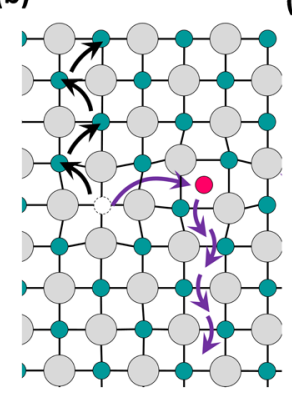

Frenkel defects (d)

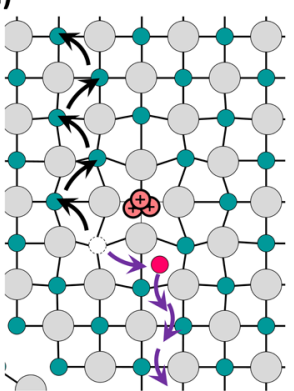

Lattice distortion by accumulated charges (e)

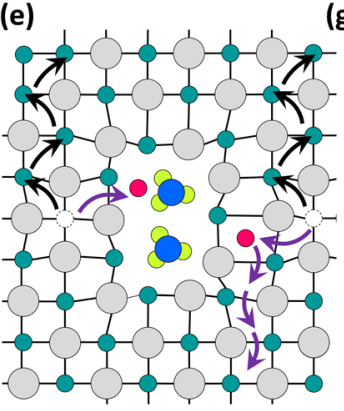

Lattice distortion by dissolved impurities (g)

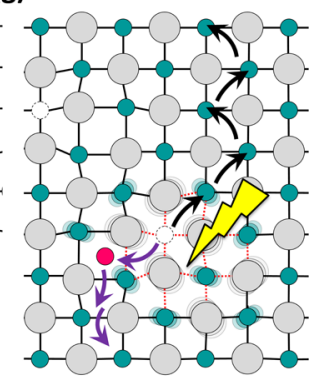

Soften lattice

by lamination

(c)

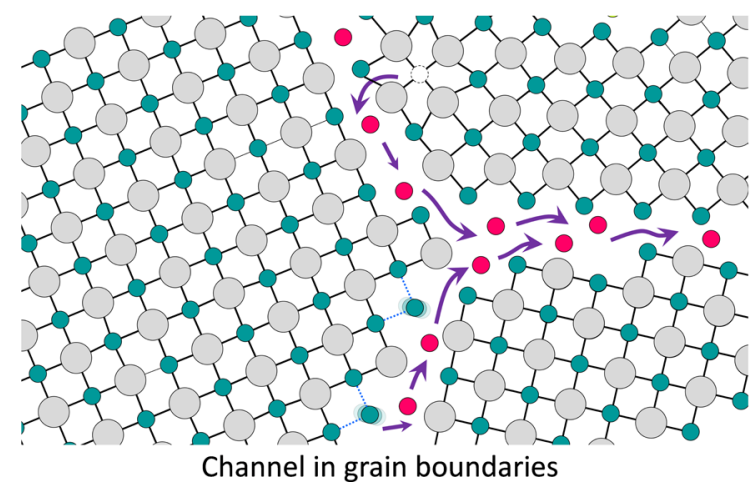

(f)

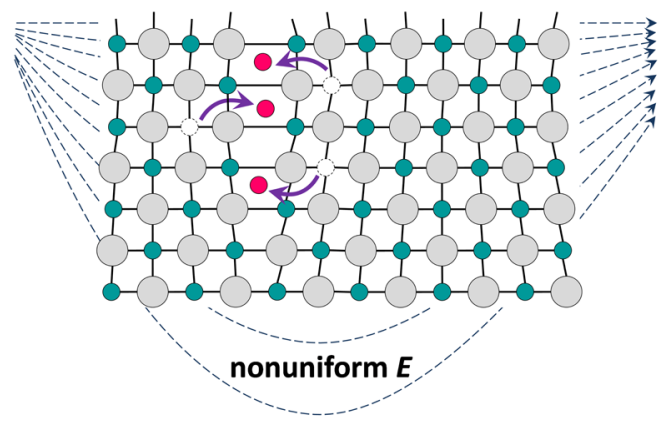

Strain induced extended defects by piezoelectric effect

Figure 3. Illustration of the ion migration pathways enabled by (a) Schottky defects, (b) Frenkel defects, (c) open space and wrong bonds at grain boundaries, $(\mathrm{d}-\mathrm{f})$ lattice distortions due to accumulated charges $(\mathrm{d})$, dissolved impurities (e), and nonuniform strain caused by piezoelectric effect (f), and (g) Soften lattice caused by the light illumination induced bond weakening.

which is direct evidence for $\mathrm{MA}^{+}$migration. In Yuan et al.'s study, the $E_{\mathrm{A}}$ for ion migration was estimated from the conductivity $(\sigma)$ changes of the $\mathrm{MAPbI}_{3}$ film at different temperatures. The measured $E_{\mathrm{A}}$ of $0.36 \mathrm{eV}$ is somewhat smaller than the value for $\mathrm{MA}^{+}$ions predicted by the first principles method $(0.46$ or $0.84 \mathrm{eV}) .{ }^{10}$ The inconsistency is not surprising because the calculated $E_{\mathrm{A}}$ is responsible to the ion migration occurring in a bulk crystal, while the measured ionic conductivity might be dominated by the ion migration at grain boundaries. Further studies on ionic conductivity using single crystals might help resolve this discrepancy. Another possibility is that the measured $E_{\mathrm{A}}$ represents the migration of other ions, such as $\mathrm{I}^{-}$. Nevertheless no obvious $\mathrm{I}^{-}$redistribution was observed within the resolution of energy-dispersive $\mathrm{X}$-ray spectroscopy $(\mathrm{EDX}) .^{11}$

Although theoretical calculations predicted the $\mathrm{I}^{-}$ions to be the most mobile ions in the $\mathrm{MAPbI}_{3}$ films, the migration of $\mathrm{I}^{-}$ ion at room temperature under device operation conditions has not been verified yet. Whether $\mathrm{I}^{-}$ions migrate at room temperature remains elusive. Yang et al. offered a hint pointing to possible $\mathrm{I}^{-}$migration at elevated temperature. ${ }^{16}$ In their study, the $\mathrm{MAPbI}_{3}$ film was embedded in a solid-state electrochemical cell with the structure $\mathrm{Pb}$-anode $/ \mathrm{MAPbI}_{3} /$ AgI/Ag-cathode. After application of a DC bias for a week at $323 \mathrm{~K}$ (Tubandt's method), formation of lead iodide $\left(\mathrm{PbI}_{2}\right)$ at the $\mathrm{Pb}$-anode $/ \mathrm{MAPbI}_{3}$ interface was observed, which could be the reaction product of the migrated $\mathrm{I}^{-}$with the $\mathrm{Pb}$-anode. However, it can also be explained by the decomposition of the $\mathrm{MAPbI}_{3}$ due to the leaving of $\mathrm{MA}^{+}$from the region close to the anode, which was observed in Xiao's study. ${ }^{3}$ In another investigation, Yuan et al. studied the electrical poling effect on the lateral $\mathrm{MAPbI}_{3}$ solar cells at elevated temperature of $330 \mathrm{~K}$ and observed the formation of a " $\mathrm{PbI}_{2}$ thread" with a width of $5-15 \mu \mathrm{m}$ that could migrate along the applied electrical field (3 $\mathrm{V} / \mu \mathrm{m}$, Figure $2 \mathrm{~d}){ }^{12}$ The migration of the $\mathrm{PbI}_{2}$ thread was explained by a field-driven reversible conversion between $\mathrm{MAPbI}_{3}$ and $\mathrm{PbI}_{2}$ phases due to a massive migration of $\mathrm{MA}^{+}$ ions and $\mathrm{I}^{-}$ions. This provided the first experimental evidence for the massive migration of $\mathrm{I}^{-}$vacancies in macroscale at elevated temperature. This result supports that both the $\mathrm{MA}^{+}$ ions and $\mathrm{I}^{-}$ions migrate in the $\mathrm{MAPbI}_{3}$ films at a relative small electrical field of $3 \mathrm{~V} / \mu \mathrm{m}$ at $330 \mathrm{~K}$, while the $\mathrm{Pb}^{2+}$ remains immobile within the resolution of the EDX measurement. Meanwhile, the experimental study of migration of $\mathrm{H}^{+}$is challenging because of the potential severe contamination issues and difficulty in measuring $\mathrm{H}^{+}$distribution, which might need to resort neutron scattering study in the future.

\section{WHAT ARE THE ION MIGRATION CHANNELS IN SOLID PEROVSKITE FILMS?}

Understanding how the mobile ions migrate under electric fields in perovskite films is of great importance since it could provide hints for the development of OTP materials with improved stability for solar cell application. Like diffusion processes, ion migration under electric field must be mediated by the defects in perovskite solid films. The fact that the OTP single crystals have much narrower X-ray diffraction peaks than those polycrystalline films indicates that the regular thin films have a large density of point defects or lattice distortion. Theoretical calculations indicate that $\mathrm{Pb}^{2-}$ vacancies or $\mathrm{MA}^{+}$ interstitials have low formation energy in $\mathrm{MAPbI}_{3}$ films, but there have been no experiment evaluation of this prediction yet. ${ }^{15} \mathrm{~A}$ large density of point defects could be generated in the OTP films for solar cells because (1) the quick formation of 
OTP films or crystallization of grains at low temperature by solution or thermal-evaporation processes, which are broadly applied for solar cell film fabrication, inevitably generate many defects in perovskite films, (2) in many cases, the precursor ratio is not stoichiometric in fabricating the high performance OTP solar cells, ${ }^{17}$ and (3) theoretically $\mathrm{MAPbI}_{3}$ has a very low calculated decomposition energy barrier of $0.1 \mathrm{eV}$ due to the "softness" of the chemical bonding. ${ }^{18}$ The easy-decomposition nature of $\mathrm{MAPbI}_{3}$ has the same origin as the low defectformation energy. Kim et al. calculated that the formation energy of $\mathrm{Pb}-\mathrm{I}$ vacancy pairs (Schottky defects, Figure 3a) in $\mathrm{MAPbI}_{3}$ film is only $27-73 \mathrm{meV} .{ }^{19}$ The "softness" also explains why the $E_{\mathrm{A}}$ for ion migration in $\mathrm{MAPbI}_{3}(0.36 \mathrm{eV})$ with large atoms is smaller than that of other perovskite oxides with smaller atoms, such as $\mathrm{LaFeO}_{3}(0.77 \mathrm{eV}), \mathrm{LaMnO}_{3}(0.73 \mathrm{eV})$, and $\mathrm{LiNbO}_{3}(0.75 \mathrm{eV})$.

In addition to bulk point defects, the surface and grain boundaries of the crystal grain are other extremely important ion migration channels (Figure 3c). The reported models only considered the ion migration through the bulk point defects, while Xiao et al.'s switchable photovoltaic study already showed that ion migration might be dominated by the grain boundaries in polycrystalline films, because the devices with large-grain films were much more difficult to switch than small-grain films. ${ }^{3}$ Due to the relatively open structure at grain boundaries and surfaces, the $E_{\mathrm{A}}$ for ion migration at grain boundaries and surfaces is roughly half that in the bulk since only half of the chemical bonds are reserved. In addition, most of the solar cell films go through a thermal-annealing process, which might evaporate partial organic species away from the grain boundaries, leaving relatively open space at grain boundaries. ${ }^{20}$ Despite the much lower $E_{\mathrm{A}}$, the ion migration cross-section area along grain boundaries is much smaller than that for bulk migration. Therefore, more studies, both theoretical and experimental, are needed to find out which channel dominates the ion migration in regular polycrystalline thin films used for solar cells. In Yuan et al.'s study of ion migration in a polycrystalline film along the lateral direction, it was found that some ions began to move at a relative smaller electrical field of $\sim 0.1 \mathrm{~V} / \mu \mathrm{m}$ (named "fast ions") and some ions began to move at electrical field of $>0.3 \mathrm{~V} / \mu \mathrm{m}$ (named "slow ions"). The origins of "fast ions" and "slow ions" have not been identified yet, which may be caused by ion migration through different channels, that is, through the bulk or the grain boundaries or film surface, by the migration of different species with different $E_{\mathrm{A}}$, or by the combination of them. ${ }^{11}$

In addition, there are some other possibilities for the generation of ion migration channels, such as the local lattice distortion caused by mesoporous scaffold confinement, ${ }^{21}$ accumulated charges (Figure $3 \mathrm{~d}$ ), ${ }^{22}$ small dissolved clusters due to absorbed molecules (Figure $3 \mathrm{e}$ ), ${ }^{23}$ and strains due to piezoelectric effect (Figure 3f). Choi et al. found that most $\mathrm{MAPbI}_{3}$ (70\%) within the mesoporous $\mathrm{TiO}_{2}$ was highly disordered with local perovskite coherence length of only 1.4 $\mathrm{nm}$, which might explain more severe photocurrent hysteresis in mesoporous structure devices in addition to the trapping effect. ${ }^{21}$ It is known that OTP can easily absorb many kinds of chemicals, such as moisture ${ }^{24}$ and polar organic molecules, like dimethylformamide (DMF), 25 dimethyl sulfoxide (DMSO), ${ }^{17 b, 18,23}$ and MA. ${ }^{26}$ These residual molecules in OTP films can open up the crystal structure significantly, which facilitates ion migration. Wu et al. studied charge accumulation in OTP based solar cells and suggested possible lattice distortion caused by accumulated charges, which was used to explain the observed device hysteresis. ${ }^{22}$ Dong et al. observed electrical field-induced strain in OTP single crystals due to their piezoelectric nature, which promotes ion migrations. $^{27}$ In addition, Gottesman et al.'s calculation suggests a reduced binding between $\mathrm{MA}^{+}$and the inorganic frame under illumination. ${ }^{28}$ This photoinduced lattice softness also increases the defect formation and thus ion migration (Figure 3g).

\section{IMPACT OF THE ION MIGRATION ON PHOTOVOLTAIC EFFICIENCY AND STABILITY}

It is now broadly believed that ion migration can cause the notorious photocurrent hysteresis problem. ${ }^{3,29}$ The photocurrent hysteresis brings difficulty in accurate characterization of the device efficiency, and there are also concerns that ion migration impairs the stability of the OTP solar cells. One example is the occurrence of serious phase segregation in mixed halide $\mathrm{MAPbBr}_{x} \mathrm{I}_{3-x}$ films under illumination as observed by Hoke et al. ${ }^{30}$ The homogeneous $\mathrm{MAPbBr}_{x} \mathrm{I}_{3-x}$ films on a mesoporous scaffold were shown to be unstable under illumination with a photoexcited phase-separation into two phases, one iodine-rich phase and one iodine-poor phase, as proven by the splitting of X-ray diffraction (XRD) peaks and PL peaks (Figure $4 a, b){ }^{30}$ The lower bandgap phase thus acts as a charge trap, which was hypothesized to be responsible to the severely reduced open circuit voltage $\left(V_{\mathrm{OC}}\right)$ and power conversion efficiency (PCE) of the $\mathrm{MAPbBr}_{x} \mathrm{I}_{3-x}$ devices. The $E_{\mathrm{A}}$ for halide-ion migration measured by Hoke et al. was $\sim 0.27$ $\mathrm{eV}$, which is close to that of halide ion migration in other pure halide perovskite materials, such as $\mathrm{MAPbI}_{3}, \mathrm{CsPbCl}_{3}$, or $\mathrm{CsPbBr}_{3}$. The much stronger ion migration in the mixed halide perovskite might be caused by the lattice mismatch with different halide anion radius. This halide segregation in $\mathrm{MAPbBr}_{x} \mathrm{I}_{3-x}$ was shown to be reversible when the films were stored in the dark for a few minutes, indicating that the $\mathrm{MAPbBr}_{x} \mathrm{I}_{3-x}$ film has different stable states in the dark and under illumination. Further study is needed to find out whether this is a spinodal decomposition. ${ }^{31}$ It is not clear whether the photoinduced lattice softness effect proposed by Gottesman et al. contributes to the ion migration induced by light illumination. ${ }^{28}$ On the other hand, it is of interest to find out whether this ion migration is promoted by the local electrical field caused by the redistribution of photogenerated charge carriers or trapped charges. More insights are needed regarding the role of light illumination in favoring ion migration.

On the other hand, ion migration does not necessarily cause the reduction of device efficiency or stability. In Xiao et al.'s study with a device structure of indium tin oxide (ITO)/ poly(3,4-ethylenedioxythiophene)-polystyrenesulfonate (PEDOT:PSS)/perovskite/Au, electric poling caused ion migration generated $\mathrm{p}-\mathrm{i}-\mathrm{n}$ structure, which resulted in a switchable short circuit current $\left(J_{\mathrm{SC}}\right)$ of $\sim 20 \mathrm{~mA} / \mathrm{cm}^{2}$ and a switchable $V_{\mathrm{OC}}$ of $\sim 1 \mathrm{~V}$. This demonstrates that the ion redistribution has an overwhelming tuning effect on the photovoltaic effect and efficiency. The electric poling can also induce the formation of lateral $\mathrm{p}-\mathrm{i}-\mathrm{n}$ structure, which enables coplanar structure in solar cells. Lateral OTP solar cell arrays with the formed $\mathrm{p}-\mathrm{i}-\mathrm{n}$ junctions connected in series were demonstrated, which output a very large $V_{\mathrm{OC}}$ of $70 \mathrm{~V}$ and have potential in eliminating the use of expensive transparent electrodes. ${ }^{11}$ One potential issue is again the stability of the doping structure. The doping formed by electric poling is caused by the accumulated defects through 
(a)

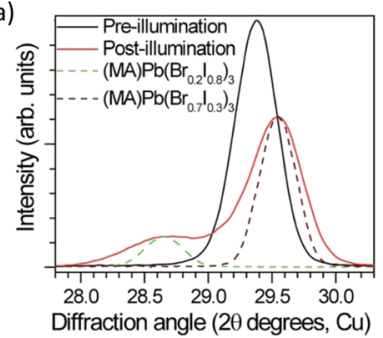

(c)

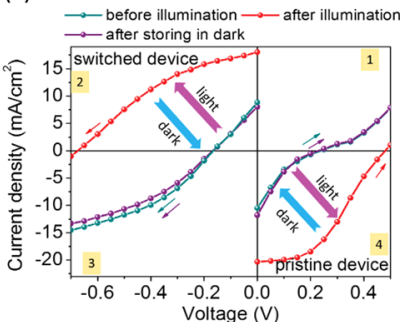

e)

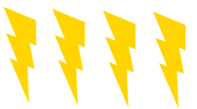

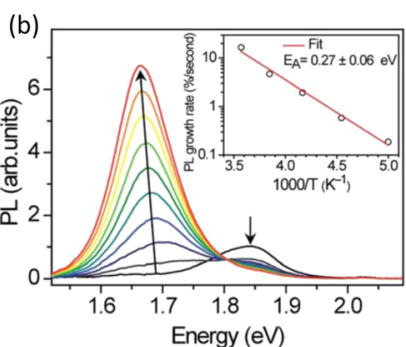

(d)

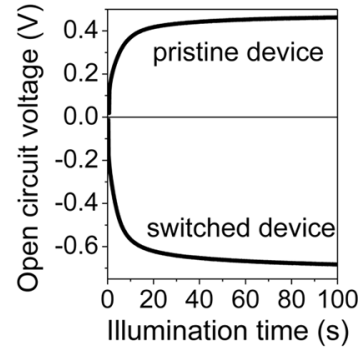

f)

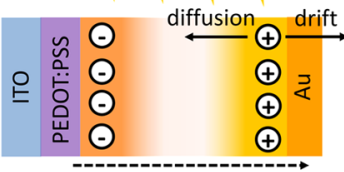

Photovoltage induced electric field

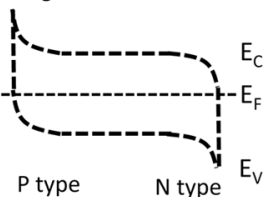

๑ Positively charged ions/vacancies $\odot$ Negative space charges

Figure 4. (a) XRD peak of a $\mathrm{MAPbBr}_{0.6} \mathrm{I}_{2.4}$ film before and after light illumination. (b) Photoluminescence spectrum change caused by the photoinduced phase separation in the $\mathrm{MAPbBr}_{0.4} \mathrm{I}_{2.6}$ film. Reproduced with permission form ref 30. Copyright 2015 Royal Society of Chemistry. (c, d) $J-V$ and steady photocurrents of perovskite solar cells with a structure of ITO/PEDOT:PSS/MAPbI $/ 3 / \mathrm{Au}$. (e, f) Illustration of ion migration and energy diagram of the device before and after light-soaking. Reproduced with permission form ref 32 . Copyright 2015 Wiley.

ion migration, while the ion back diffusion in the absence of the applied field could eventually annul the doping effect, which was observed to occur in a few days after poling.

Further studies carried out on lateral solar cells confirmed that ions in $\mathrm{MAPbI}_{3}$ started to migrate at a small electrical field of $0.3 \mathrm{~V} / \mu \mathrm{m},{ }^{11}$ which is much smaller than the built-in electrical field in most of the OTP solar cells $(\sim 3 \mathrm{~V} / \mu \mathrm{m})$. This suggests that the ion migration already occurred after the device was formed and a balance had been reached. It is noted that the photovoltage induced additional electric field is comparable to the built-in electric field, which should also cause ion back migration when the device is under illumination. In Deng et al.'s study, it was found that the light induced self-poling effect (LISP) had the same effect as electric poling (Figure $4 \mathrm{c}, \mathrm{d}$ ). ${ }^{32}$ The pristine device started with a poor performance before illumination, that is, an initial $V_{\mathrm{OC}}$ of $0.66 \mathrm{~V}$ and efficiency of $4.3 \%$. After illumination of the device under one sun for tens of seconds, the $V_{\mathrm{OC}}$ increased to $1.02 \mathrm{~V}$ and the device efficiency increased to $8.1 \%$. This can be explained by the ion migration

driven by the photovoltage promoting the formation of a favorable $\mathrm{p}-\mathrm{i}-\mathrm{n}$ structure. This discovery is very promising, because it implies that the ion migration in OTP solar cells actually improves device efficiency rather than reducing device efficiency. It also explains that why the state-of-the-art perovskite solar cells still have a very long lifetime of thousand hours at accelerated testing conditions where the presence of ion migration under illumination is expected. ${ }^{33}$ The LISP effect should be general and independent of the device structures. It has been sometimes ignored, because usually the devices have been unintentionally illuminated by strong light at open-circuit conditions before $J-V$ measurement or the devices have been optimized to have maximum efficiency or suppressed ion migration.

\section{SUPPRESSION OF ION MIGRATION IN OTP FILMS}

Although it is not known yet whether the presence of ion migration is beneficial or harmful to the long-term stability of the OTP solar cells, there have been tremendous efforts to eliminate the photocurrent hysteresis caused by ion migration. To suppress the ion migration in OTPs, the first question to be identified is through which channel, grain boundary or bulk, ions migrate dominantly in regular polycrystalline solar cell films.

Recent studies showed that ion migration through grain boundaries might dominate although bulk migration cannot be completely excluded. One typical observation is that the devices with large OTP grains generally have less photocurrent hysteresis. ${ }^{34}$ Among all the device structure reported, the "inverted" planar heterojunction structure device with a fullerene buffer layer generally does not show photocurrent hysteresis. ${ }^{17 b}$ It was explained by Shao et al. that fullerene could diffuse into grain boundaries and passivate the charge traps at OTP grain surface and grain boundaries (Figure $5 \mathrm{a}, \mathrm{b}) .{ }^{17 \mathrm{~b}, 35} \mathrm{In}$ explaining the trap-passivation effect by fullerene, $\mathrm{Xu}$ et al. proposed that the interaction of fullerene with $\mathrm{I}-\mathrm{Pb}$ antisite defects could eliminate the deep traps caused by them, which was supported by the DFT calculation (Figure $5 \mathrm{c}, \mathrm{d}$ ). ${ }^{36}$ We speculate that the fullerene-defect interaction at grain boundaries also reduces the ion diffusion by blocking the grain boundary channels, as well as strengthens the bonding.

The recent demonstration of photostable $\mathrm{MAPbBr}_{x} \mathrm{I}_{3-x}$ mixed halide perovskite also highlighted the importance of improved crystallinity and reduced grain boundary area in stabilizing the material under illumination. By replacing PEDOT:PSS with a nonwetting hole transport layer of poly(triarylamine) (PTAA), Bi et al. increased the grain lateral size of $\mathrm{MAPbI}_{3}$ to be several times larger than film thickness. ${ }^{38}$ $\mathrm{Hu}$ et al. applied this technique to increase the grain size of $\mathrm{MAPbBr}_{x} \mathrm{I}_{3-x}(x<1)$ films from $\sim 200 \mathrm{~nm}$ to $>1 \mu \mathrm{m} .{ }^{37} \mathrm{XRD}$ and other optical measurements proved that the photoinduced phase separation in $\mathrm{MAPbBr}_{x} \mathrm{I}_{3-x}$ did not occur in the film with large grains (Figure $5 \mathrm{~g}, \mathrm{~h}$ ). Meanwhile, the efficiency and stability of the $\mathrm{MAPbBr}_{x} \mathrm{I}_{3-x}$ solar cells was also significantly increased due to the absence of low-bandgap impurity phase and reduced grain boundary traps.

If bulk ion migration is also severe, particularly under illumination, the chemical structures of hybrid perovskite will have to be modified. Increasing the valence charges of the ions is an approach to increase the Columbic interaction between the ions and the crystal frame, which is a general way to reduce ion migrations. Codoping cations with higher and lower valence ions might be another possible strategy. ${ }^{39}$ However, the 
(a)

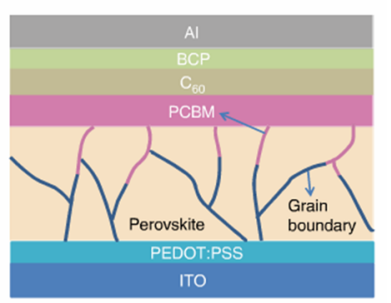

(c)
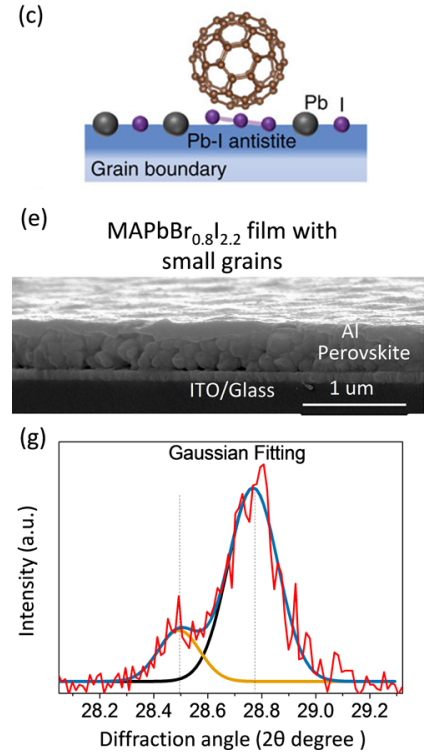

(b)

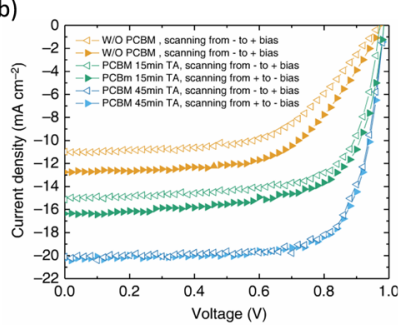

(d)

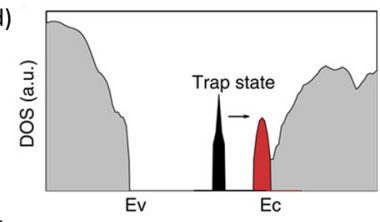

(f)
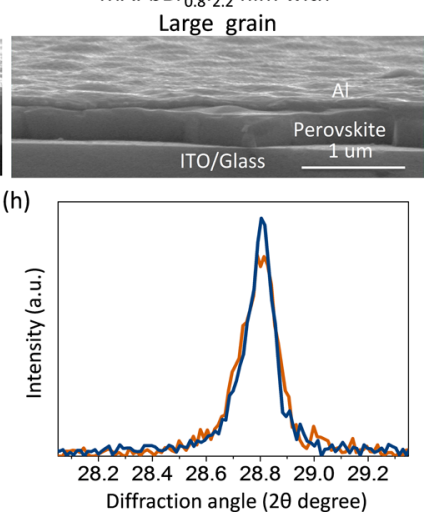

Figure 5. (a) Illustration of the passivation of $\mathrm{MAPbI}_{3}$ grain boundaries and grain surface by PCBM. (b) Suppressed $J-V$ hysteresis by PCBM passivation; Reproduced with permission from ref 35 . Copyright 2014 Nature Publishing Group. (c) Illustration of the passivation of $\mathrm{Pb}-\mathrm{I}$ antisite defect by PCBM. (d) Calculated density of states of $\mathrm{MAPbI}_{3}$ with unpassivated $\mathrm{Pb}-\mathrm{I}$ antisite (black) and PCBM passivated $\mathrm{Pb}-\mathrm{I}$ antisite (red). Reproduced with permission from ref 36. Copyright 2015 Nature Publishing Group; (e, f) SEM images of $\mathrm{MAPbBr}_{0.8} \mathrm{I}_{2.2}$ film with small (e) and large (f) grain size, respectively. (g) Photoinduced splitting of (200) XRD peak of the $\mathrm{MAPbBr}_{0.8} \mathrm{I}_{2.2}$ film with small grain size. (h) Unchanged (200) XRD peak of $\mathrm{MAPbBr}_{0.8} \mathrm{I}_{2.2}$ film with large grain size under illumination. Reproduced with permission from ref 37. Copyright 2015 Wiley.

modification of perovskite structure might also take away the fantastic optoelectronic properties of the hybrid perovskite, which give rise to the extraordinary photovoltaic performance. Further understanding of why hybrid perovskite materials work so well for photovoltaics is thus needed to guide the material structure design.

\section{CONCLUSIONS AND OUTLOOK}

There has been tremendous understanding of ion migration in the OTPs in such a short time. Much direct and indirect evidence overwhelmingly confirmed that ion migration occurs in OTP polycrystalline materials in many circumstances. So far, more studies are needed to address many still open questions to fully understand its impact to perovskite solar cell performance, such as the following: (1) Do $\mathrm{I}^{-}$and $\mathrm{H}^{+}$ions migrate at room temperature in solar grade perovskite films? (2) Is ion migration present in optimized devices that do not show photocurrent hysteresis? (3) What are the major ion migration channels in polycrystalline solar cell films? (4) Does ion migration impact the long-term stability of the solar cells?

(5) How should we change the structure of OTPs to suppress the ion migration without impacting their optoelectronic properties?

\section{AUTHOR INFORMATION}

\section{Corresponding Author}

*E-mail: jhuang2@unl.edu.

\section{Funding}

This work was supported by National Science Foundation Grant DMR-1505535 and Grant DMR-1420645.

Notes

The authors declare no competing financial interest.

\section{Biographies}

Yongbo Yuan received his Ph.D. degree from Sun Yat-sen University (China) in 2009. He is currently a research scientist in Dr. Jinsong Huang's research group in the Department of Mechanical and Materials Engineering of the University of Nebraska-Lincoln. His research interests include solution processed optoelectronic devices such as solar cells, thin film transistors, and photodetectors.

Jinsong Huang received his Ph.D. degree from the University of California-Los Angeles in 2007. He is now a Susan J. Rosowski Associate Professor in the Department of Mechanical and Materials Engineering at the University of Nebraska-Lincoln. His current research interests include solution processed electronic materials for applications in sensing, energy, and consumer electronics.

\section{REFERENCES}

(1) Mizusaki, J.; Arai, K.; Fueki, K. Ionic conduction of the perovskite-type halides. Solid State Ionics 1983, 11, 203-211.

(2) (a) Snaith, H. J.; Abate, A.; Ball, J. M.; Eperon, G. E.; Leijtens, T.; Noel, N. K.; Stranks, S. D.; Wang, J. T.-W.; Wojciechowski, K.; Zhang, W. Anomalous hysteresis in perovskite solar cells. J. Phys. Chem. Lett. 2014, 5, 1511-1515. (b) Unger, E.; Hoke, E.; Bailie, C.; Nguyen, W.; Bowring, A.; Heumüller, T.; Christoforo, M.; McGehee, M. Hysteresis and transient behavior in current-voltage measurements of hybridperovskite absorber solar cells. Energy Environ. Sci. 2014, 7, 36903698. (c) Jeon, N.; Noh, J.; Kim, Y.; Yang, W.; Ryu, S. Solvent engineering for high-performance inorganic-organic hybrid perovskite solar cells. Nat. Mater. 2014, 13, 897-903.

(3) Xiao, Z.; Yuan, Y.; Shao, Y.; Wang, Q.; Dong, Q.; Bi, C.; Sharma, P.; Gruverman, A.; Huang, J. Giant switchable photovoltaic effect in organometal trihalide perovskite devices. Nat. Mater. 2015, 14, 193198.

(4) Tress, W.; Marinova, N.; Moehl, T.; Zakeeruddin, S.; Nazeeruddin, M. K.; Grätzel, M. Understanding the rate-dependent $\mathrm{J}-\mathrm{V}$ hysteresis, slow time component, and aging in $\mathrm{CH} 3 \mathrm{NH} 3 \mathrm{PbI} 3$ perovskite solar cells: the role of a compensated electric field. Energy Environ. Sci. 2015, 8, 995-1004.

(5) (a) Wang, Q.; Shao, Y.; Xie, H.; Lyu, L.; Liu, X.; Gao, Y.; Huang, J. Qualifying composition dependent $\mathrm{p}$ and $\mathrm{n}$ self-doping in CH3NH3PbI3. Appl. Phys. Lett. 2014, 105, 163508. (b) Dong, Q.; Fang, Y.; Shao, Y.; Mulligan, P.; Qiu, J.; Cao, L.; Huang, J. Electronhole diffusion lengths $>175 \mu \mathrm{m}$ in solution grown $\mathrm{CH} 3 \mathrm{NH} 3 \mathrm{PbI} 3$ single crystals. Science 2015, 347, 967-970.

(6) Chin, X. Y.; Cortecchia, D.; Yin, J.; Bruno, A.; Soci, C. Lead iodide perovskite light-emitting field-effect transistor. Nat. Commun. 2015, 6, 7383.

(7) Juarez-Perez, E. J.; Sanchez, R. S.; Badia, L.; Garcia-Belmonte, G.; Kang, Y. S.; Mora-Sero, I.; Bisquert, J. Photoinduced giant dielectric constant in lead halide perovskite solar cells. J. Phys. Chem. Lett. 2014, 5, 2390-2394. 
(8) Lin, Q.; Armin, A.; Nagiri, R. C. R.; Burn, P. L.; Meredith, P. Electro-optics of perovskite solar cells. Nat. Photonics 2014, 9, 106112.

(9) Egger, D. A.; Kronik, L.; Rappe, A. M. Theory of hydrogen migration in organic-inorganic halide perovskites. Angew. Chem., Int. Ed. 2015, 54, 12437-12441.

(10) Eames, C.; Frost, J. M.; Barnes, P. R.; O'regan, B. C.; Walsh, A.; Islam, M. S. Ionic transport in hybrid lead iodide perovskite solar cells. Nat. Commun. 2015, 6, 7497.

(11) Yuan, Y.; Chae, J.; Shao, Y.; Wang, Q.; Xiao, Z.; Centrone, A.; Huang, J. Photovoltaic Switching Mechanism in Lateral Structure Hybrid Perovskite Solar Cells. Adv. Energy Mater. 2015, 5, 1500615.

(12) Yuan, Y.; Wang, Q.; Shao, Y.; Lu, H.; Li, T.; Gruverman, A.; Huang, J. Electric Field Driven Reversible Conversion between Methylammonium Lead Triiodide Perovskites and Lead Iodide at Elevated Temperature. Adv. Energy Mater. 2016, 6, 1501803.

(13) Azpiroz, J. M.; Mosconi, E.; Bisquert, J.; De Angelis, F. Defects Migration in Methylammonium Lead Iodide and their Role in Perovskite Solar Cells Operation. Energy Environ. Sci. 2015, 8, 21182127.

(14) Haruyama, J.; Sodeyama, K.; Han, L.; Tateyama, Y. FirstPrinciples Study of Ion Diffusion in Perovskite Solar Cell Sensitizers. J. Am. Chem. Soc. 2015, 137, 10048-10051.

(15) Yin, W.-J.; Shi, T.; Yan, Y. Unusual defect physics in CH3NH3PbI3 perovskite solar cell absorber. Appl. Phys. Lett. 2014, 104, 063903.

(16) Yang, T. Y.; Gregori, G.; Pellet, N.; Grätzel, M.; Maier, J. The Significance of Ion Conduction in a Hybrid Organic-Inorganic LeadIodide-Based Perovskite Photosensitizer. Angew. Chem., Int. Ed. 2015, 54, 7905-7910.

(17) (a) Chen, Q.; De Marco, N.; Yang, Y. M.; Song, T.-B.; Chen, C.C.; Zhao, H.; Hong, Z.; Zhou, H.; Yang, Y. Under the spotlight: The organic-inorganic hybrid halide perovskite for optoelectronic applications. Nano Today 2015, 10, 355-396. (b) Wang, Q.; Shao, Y.; Dong, Q.; Xiao, Z.; Yuan, Y.; Huang, J. Large fill-factor bilayer iodine perovskite solar cells fabricated by a low-temperature solutionprocess. Energy Environ. Sci. 2014, 7, 2359-2365.

(18) Buin, A.; Pietsch, P.; Xu, J.; Voznyy, O.; Ip, A. H.; Comin, R.; Sargent, E. H. Materials processing routes to trap-free halide perovskites. Nano Lett. 2014, 14, 6281-6286.

(19) Kim, J.; Lee, S.-H.; Lee, J. H.; Hong, K.-H. The role of intrinsic defects in methylammonium lead iodide perovskite. J. Phys. Chem. Lett. 2014, 5, 1312-1317.

(20) (a) Dong, R.; Fang, Y.; Chae, J.; Dai, J.; Xiao, Z.; Dong, Q.; Yuan, Y.; Centrone, A.; Zeng, X. C.; Huang, J. High-Gain and LowDriving-Voltage Photodetectors Based on Organolead Triiodide Perovskites. Adv. Mater. 2015, 27, 1912-1918. (b) Chen, Q.; Zhou, H.; Song, T.-B.; Luo, S.; Hong, Z.; Duan, H.-S.; Dou, L.; Liu, Y.; Yang, Y. Controllable self-induced passivation of hybrid lead iodide perovskites toward high performance solar cells. Nano Lett. 2014, $14,4158-4163$.

(21) Choi, J. J.; Yang, X.; Norman, Z. M.; Billinge, S. J.; Owen, J. S. Structure of methylammonium lead iodide within mesoporous titanium dioxide: active material in high-performance perovskite solar cells. Nano Lett. 2014, 14, 127-133.

(22) Wu, B.; Fu, K.; Yantara, N.; Xing, G.; Sun, S.; Sum, T. C.; Mathews, N. Charge Accumulation and Hysteresis in Perovskite-Based Solar Cells: An Electro-Optical Analysis. Adv. Energy Mater. 2015, 5, 1500829.

(23) Jeon, N. J.; Noh, J. H.; Kim, Y. C.; Yang, W. S.; Ryu, S.; Seok, S. I. Solvent engineering for high-performance inorganic-organic hybrid perovskite solar cells. Nat. Mater. 2014, 13, 897-903.

(24) You, J.; Yang, Y. M.; Hong, Z.; Song, T.-B.; Meng, L.; Liu, Y.; Jiang, C.; Zhou, H.; Chang, W.-H.; Li, G.; Yang, Y. Moisture assisted perovskite film growth for high performance solar cells. Appl. Phys. Lett. 2014, 105, 183902.

(25) Xiao, Z.; Dong, Q.; Bi, C.; Shao, Y.; Yuan, Y.; Huang, J. Solvent Annealing of Perovskite-Induced Crystal Growth for PhotovoltaicDevice Efficiency Enhancement. Adv. Mater. 2014, 26, 6503-6509.
(26) Zhou, Z.; Wang, Z.; Zhou, Y.; Pang, S.; Wang, D.; Xu, H.; Liu, Z.; Padture, N. P.; Cui, G. Methylamine-Gas-Induced Defect-Healing Behavior of $\mathrm{CH} 3 \mathrm{NH} 3 \mathrm{PbI} 3$ Thin Films for Perovskite Solar Cells. Angew. Chem., Int. Ed. 2015, 54, 9705-9709.

(27) Dong, Q.; Song, J.; Fang, Y.; Shao, Y.; Ducharme, S.; Huang, J. Lateral-Structure Single-Crystal Hybrid Perovskite Solar Cells Through Piezoelectric Poling. Adv. Mater. 2015, manuscript in preparation.

(28) Gottesman, R.; Haltzi, E.; Gouda, L.; Tirosh, S.; Bouhadana, Y.; Zaban, A.; Mosconi, E.; De Angelis, F. Extremely slow photoconductivity response of $\mathrm{CH} 3 \mathrm{NH} 3 \mathrm{PbI} 3$ perovskites suggesting structural changes under working conditions. J. Phys. Chem. Lett. 2014, 5, 2662-2669.

(29) (a) Zhang, Y.; Liu, M.; Eperon, G. E.; Leijtens, T. C.; McMeekin, D.; Saliba, M.; Zhang, W.; De Bastiani, M.; Petrozza, A.; Herz, L. M.; et al. Charge selective contacts, mobile ions and anomalous hysteresis in organic-inorganic perovskite solar cells. Mater. Horiz. 2015, 2, 315-322. (b) van Reenen, S.; Kemerink, M.; Snaith, H. J. Modeling Anomalous Hysteresis in Perovskite Solar Cells. J. Phys. Chem. Lett. 2015, 6, 3808-3814.

(30) Hoke, E. T.; Slotcavage, D. J.; Dohner, E. R.; Bowring, A. R.; Karunadasa, H. I.; McGehee, M. D. Reversible photo-induced trap formation in mixed-halide hybrid perovskites for photovoltaics. Chem. Sci. 2015, 6, 613-617.

(31) (a) Yin, W.-J.; Yang, J.-H.; Kang, J.; Yan, Y.; Wei, S.-H. Halide perovskite materials for solar cells: a theoretical review. J. Mater. Chem. A 2015, 3, 8926-8942. (b) Noh, J. H.; Im, S. H.; Heo, J. H.; Mandal, T. N.; Seok, S. I. Chemical management for colorful, efficient, and stable inorganic-organic hybrid nanostructured solar cells. Nano Lett. 2013, 13, 1764-1769.

(32) Deng, Y.; Xiao, Z.; Huang, J. Light Induced Self-Poling Effect in Organometal Trihalide Perovskite Solar Cells for Increased Device Efficiency and Stability. Adv. Energy Mater. 2015, 5, 1500721.

(33) Peplow, M. A Conversation with Henry Snaith. ACS Cent. Sci. 2015, 1, 159-160.

(34) Kim, H.-S.; Park, N.-G. Parameters affecting I-V hysteresis of $\mathrm{CH} 3 \mathrm{NH} 3 \mathrm{PbI} 3$ perovskite solar cells: effects of perovskite crystal size and mesoporous TiO2 layer. J. Phys. Chem. Lett. 2014, 5, 2927-2934.

(35) Shao, Y.; Xiao, Z.; Bi, C.; Yuan, Y.; Huang, J. Origin and elimination of photocurrent hysteresis by fullerene passivation in $\mathrm{CH} 3 \mathrm{NH} 3 \mathrm{PbI} 3$ planar heterojunction solar cells. Nat. Commun. 2014, 5,5784 .

(36) Xu, J.; Buin, A.; Ip, A. H.; Li, W.; Voznyy, O.; Comin, R.; Yuan, M.; Jeon, S.; Ning, Z.; McDowell, J. J.; et al. Perovskite-fullerene hybrid materials suppress hysteresis in planar diodes. Nat. Commun. 2015, 6, 7081.

(37) Hu, M.; Bi, C.; Yuan, Y.; Bai, Y.; Huang, J. Stabilized Wide Bandgap MAPbBrxI3-x Perovskite by Enhanced Grain Size and Improved Crystallinity. Adv. Sci. 2015, DOI: 10.1002/advs.201500301.

(38) Bi, C.; Wang, Q.; Shao, Y.; Yuan, Y.; Xiao, Z.; Huang, J. Nonwetting surface-driven high-aspect-ratio crystalline grain growth for efficient hybrid perovskite solar cells. Nat. Commun. 2015, 6, 7747.

(39) Kharton, V.; Viskup, A.; Yaremchenko, A.; Baker, R.; Gharbage, B.; Mather, G.; Figueiredo, F.; Naumovich, E.; Marques, F. Ionic conductivity of $\mathrm{La}(\mathrm{Sr}) \mathrm{Ga}(\mathrm{Mg}, \mathrm{M}) \mathrm{O} 3-\delta(\mathrm{M}=\mathrm{Ti}, \mathrm{Cr}, \mathrm{Fe}, \mathrm{Co}, \mathrm{Ni})$ : effects of transition metal dopants. Solid State Ionics 2000, 132, 119130. 